\title{
The problems of closed liver injuries ${ }^{1}$
}

\author{
R. H. B. MILLS \\ From East Glamorgan Hospital, Church Village, Nr. Pontypridd
}

SYNOPSIS Because laceration of the liver is a condition which the surgeon is rarely called upon to treat, 36 cases of liver injury admitted bətween 1926 and 1958 have been reviewed and the results compared with those of other authors. As well as discussing the incidence of this injury and its relation to age, sex, and pathology, the surgical management is outlined. The greatest single factor which has assisted the surgeon is transfusion of whole blood. Early operation is considered advisable, and suturing is preferred in repairing damage to the liver substance and achieving haemostasis. Nevertheless, the mortality rate is high, in this series $60 \%$, which compares favourably with that of other series. It is notable that patients operated on have a better chance of survival than those not operated upon.

Hepatic trauma due to external violence is not common, but is a condition which is associated with a high mortality rate. Apart from tears sustained in the course of difficult cholecystectomies, laceration of the liver due to external trauma is a condition which the average surgeon is rarely called upon to treat. Because of this, not only does one find that views in regard to the local management of the injured organ vary, but there is little known about such problems as incidence, complications, mortality rates, and treatment.

In order to try to build up some authoritative picture of this type of injury, a review of 36 cases of liver injury admitted to the Cardiff Royal Infirmary and from hospitals in four heavily industrialized mining valleys radiating from the northern boundaries of the city was undertaken. In this particular review, which covers the period 1926-58, there were 30 non-penetrating injuries confirmed either at operation or at necropsy, five presumed cases, and one of open injury.

\section{INCIDENCE}

The assessment of incidence was found to be difficult, for there were many years in which no cases were seen and information on what percentage of admissions were emergencies was not recorded. However, between 1949 and 1953 the incidence in the Cardiff Royal Infirmary was found to be 1 in 4,000, but in one valley (Pontypridd) during the years 1955-57, the incidence was 1 in 1,200. The latter

'Synopsis of a thesis accepted by the University of Cambridge in 1959 for the degree of M.D. figures compare closely with those of Edler (1887) and Thorlakson and Hay (1929), who in each case gave a figure of 1 in 1,300, whereas Wright, Prigot, and Hill (1947) found 27 cases occurring in 34,000 cases admitted to the Harlem Hospital between 1953 and 1945, a figure of 1 in 1,259.

The problems of closed splenic and renal injuries are well described in most surgical textbooks, but little is said of rupture of the liver. Because descriptions of the two former injuries are accompanied either by historical annotations or by profusely coloured illustrations, the focus of interest tends to be centred on those two organs and the impression is conveyed that they are the commonest organs to be injured in the abdominal cavity. This is far from the truth, for in this series during the only period in which complete statistics were available from all the areas under consideration, there were 11 hepatic compared with 12 splenic and 17 renal injuries. Below are summarized figures from past reviews compared with the present series, and it is surprising to see that, apart from the figures of Hinton (1929) and Clarke (1954), in all other series the liver appears to be more frequently damaged than the spleen.

\begin{tabular}{lcclll}
\multicolumn{7}{c}{ TA B LE I } \\
& Liver & Spleen & Kidney & $\begin{array}{c}\text { Pancreas Gastro- } \\
\text { intestinal } \\
\text { Tract }\end{array}$ \\
\hline Present review & 11 & 12 & 17 & 1 & 9 \\
Vance (1928) & $59 \cdot 9 \%$ & $33 \%$ & $21 \cdot 5 \%$ & $4 \cdot 4 \%$ & $18 \cdot 2 \%$ \\
Hinton (1929) & 7 & 8 & 18 & - & 12 \\
Allen (1931) & 24 & 10 & - & - & 41 \\
Lewis and Trimble & 20 & 12 & 30 & - & 39 \\
(1933) & 8 & 27 & 10 & 1 & 5 \\
Clarke (1954) & & & & & \\
\hline
\end{tabular}


AGE, SEX, AND AETIOLOGY

Of the 30 cases recorded in this review 24 males and six females were injured, a ratio of four to one. The age distribution is of interest for predominantly liver injury is an injury sustained by the young (Fig. 1).

In the present review road accidents accounted for eight cases, crushing injuries nine, direct blows on the abdomen six, falls from a height five, 'scissors' type two. In children, road accidents and dangerous play (falls from walls or trees) accounted for many cases, but over the age of 20 , although road accidents contribute to the overall figure, injury sustained in dangerous occupations is the most frequent cause. The commonest industrial injury occurred in the mines where men were crushed by derailed coal trams or buried under falls of coal. In so far as the American literature is concerned, all reviews dealing with the topic of abdominal injuries (Thorlakson and Hay, 1929; Allen, 1931; O'Neill, 1941; Papen and Mikal, 1950; Mikal and Papen, 1950; Musselman, Glas, and Campbell, 1955) showed that automobile accidents were by far the commonest cause.

The force of injury required to produce liver injury varies tremendously, from simple to the most major injuries. From an aetiological point of view closed rupture of the liver can be classified as in Table II.

There is no doubt, however, that major trauma is the causative factor in well over $99 \%$ of cases. Minor trauma is of importance where there is pathological or physiological enlargement of the liver, as in toxaemia of pregnancy or in the newborn. Spontaneous rupture is a rarity and a most doubtful entity. In all the literature studied I have only found 10 such cases. This paper deals with the type of injury most frequently seen in clinical practice, the type normally associated with trauma of varying degree, but in which there is no underlying hepatic disease.

\section{PATHOLOGY AND COMPLICATIONS}

The mechanism of liver rupture is difficult to understand for it is almost impossible to produce experimentally the type of injury seen at operation. Whatever mechanism is involved is really only of academic importance so long as it is clearly understood that the surface laceration is merely the



external evidence of generalized intrahepatic damage of unknown and varying extent, and the whole course and complications of the illness are determined by this latter factor. Three separate systems must be considered, each with its own particular problems.

DIVISION OF INTRAHEPATIC BLOOD VESSELS Haemorrhage undoubtedly constitutes the principal threat to life. A feature which is not fully realized is that the hepatic venous system is of comparable size to the portal and that tributaries of no mean diameter ramify through all parts of the liver substance. Furthermore, the point of entry of the hepatic veins in the vena cava is extremely close, within 1 in. of the right auricle. In effect, therefore, division of a hepatic vein means that these patients are virtually bleeding from the right side of the heart. It is probable that in a very high proportion of those cases in which sudden death occurred at the site of the accident it is these vessels which were torn. The percentage of patients who die at the site of the accident is difficult to determine, but Vance (1928) gave a figure of $33.3 \%$, Lamb (1939) of $43.33 \%$, and in one particular area between 1954 and 1958 in this series the figure was $50 \%$.

INTRAHEPATIC CELlULAR DAMAGE This may be diffuse and varies tremendously in extent. In two cases in this series, in which a small laceration was

TABLE II

\begin{tabular}{l} 
Traumatic \\
\hline Major Road accidents, falls from heights, crushing and buffer \\
injuries, etc. \\
Minor (1) Without underlying liver disease \\
Newborn \\
(2) With underlying liver disease \\
Pregnancy
\end{tabular}

Spontaneous

('Apoplexy of the liver') (1) Without underlying liver disease

(2) With underlying liver disease 


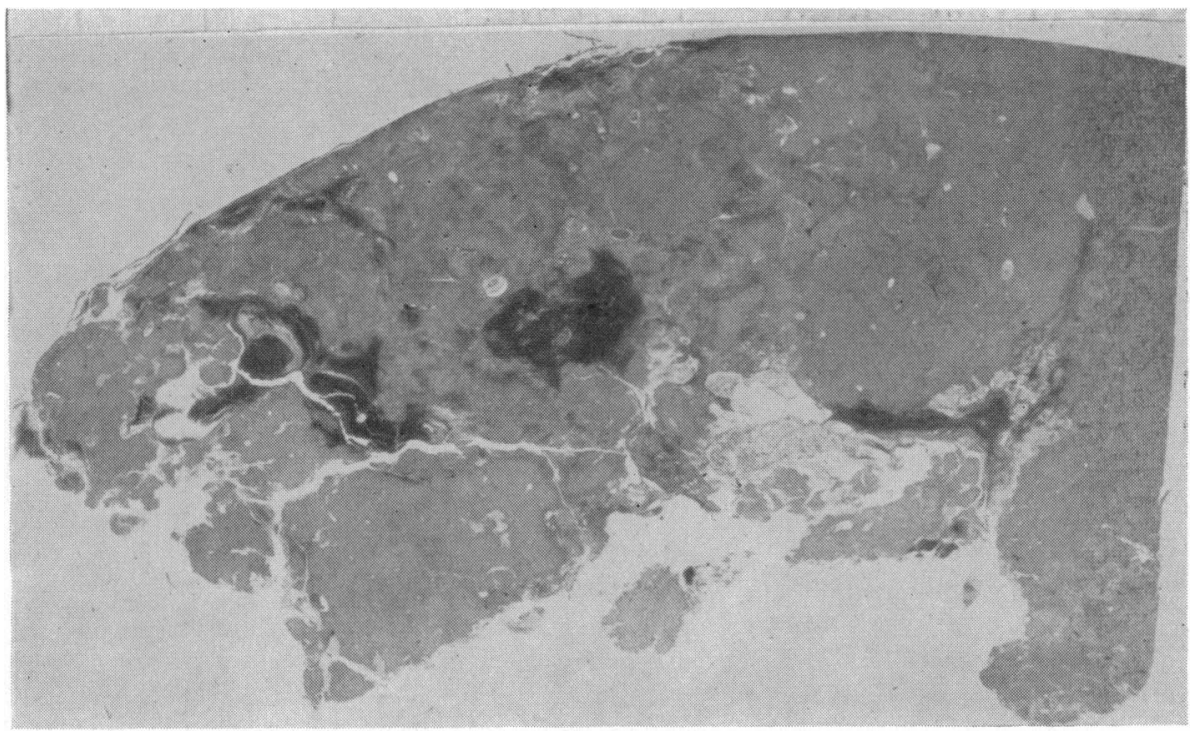

FIG. 2. Histo-

logical section of liver taken at a distance from the site of laceration, demonstrating small haemorrhagic areas.

found, scattered throughout the liver substance were multiple areas of intrahepatic haemorrhage (Fig. 2). Apart from presenting as a cause of sudden death and the common type met in clinical practice, liver injury may exceptionally present as delayed rupture or later manifestations. The mechanisms can be readily related to the underlying intrahepatic injury:

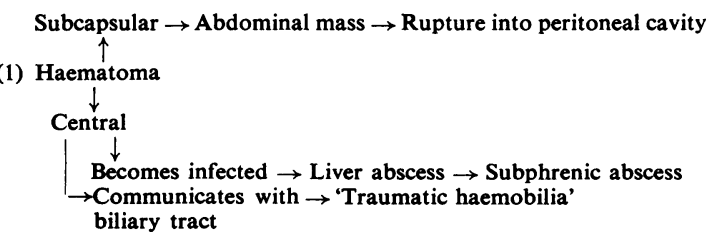

(2) Traumatic bile cyst $\rightarrow$ Presenting as an abdominal mass

$\rightarrow$ Enlarging beneath the diaphragm, dyspnoea $\rightarrow$ Rupture into peritoneal cavity

Should a subcapsular haematoma form it may enlarge in such a fashion as to present as an abdominal mass which subsequently ruptures. On the other hand, a central injury may be produced. Should this in the main be a haematoma, it may increase in size and with a varying amount of bile extend to the surface, or it may form a true bile cyst. If a central haematoma becomes infected, a liver abscess will result which commonly manifests itself at a later stage as a subphrenic abscess. Occasionally, such a haematoma communicates with a major radical of the biliary tree and the contents are discharged into the duodenum and melaena results (traumatic haemobilia).

The intrahepatic post-operative complications are

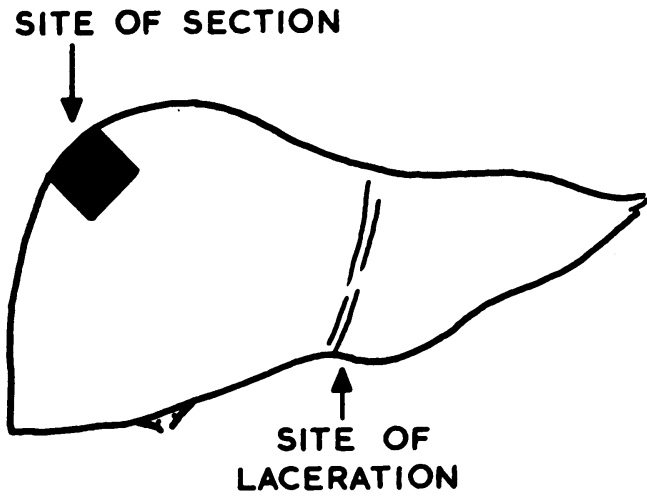

related to the extent of infarction of liver tissue Thus:

Loss of blood supply $\rightarrow$ Infarction $\rightarrow$ Necrosis $\rightarrow$ Sequestration
Subphrenic abscess $\leftarrow$ Liver abscess $\leftarrow$ Infection $\rightarrow$ Secondary
haemorrhage

When a surgeon undertakes a laparotomy for a lacerated liver he can by no means at his disposal assess the true amount of liver damage, for a small surface laceration may be accompanied by the most severe intrahepatic damage. $\mathrm{He}$ is therefore in no position to offer a prognosis as to the outcome of the operation, no matter how successful he may have been in suturing the damaged viscus.

Post-operative jaundice occurred in five cases in the present series and usually within the first week of convalescence. In part this is probably related to cellular damage, but all these cases had previously 
been given blood and it is impossible to exclude the possibility of a transfusion reaction.

DAMAGE TO THE BILIARY RADICALS When the liver is lacerated, as well as there being vascular and sinusoidal damage, fine biliary radicals are divided and bile in addition to blood pours into the peritoneal cavity. Should surgical intervention be successful in controlling haemorrhage, but fail to ensure either that no further bile flows into the peritoneal cavity or that adequate drainage for further uncontrolled biliary secretion is provided, then the majority of those intra-abdominal complications which arise in the post-operative period can be attributed to the peritoneal irritation consequent upon the biliary outflow.

In this particular series the following complications were observed: Peritonitis (4 cases), ileus ( 3 cases), intestinal obstruction ( 3 cases), residual abscess ( 1 case), and burst abdominal wound ( 2 cases).

\section{'HEPATO-RENAL SYNDROME'}

This term 'hepato-renal syndrome' is an uncertain entity and has been applied to all sorts of conditions in which terminally there is a progressive renal failure of unexplained origin. In cases of hepatic trauma it has been postulated that a nephrotoxin is elaborated by the damaged liver and on this account it was suggested by Boyce (1941) and later by Gans (1955) that this was the most important reason that 'the removal of devitalized liver tissue is indicated'. This hypothesis cannot go unchallenged and the following points summarize the arguments that can be advanced against it.

(1) Experimental injury to the liver in dogs, rats, and rabbits has been unsuccessful in producing the type of injury found in humans (Orr and Helwig, 1939; Helwig and Orr, 1932). (2) There are many cases of survival described in which $(a)$ massive liver damage was sustained, $(b)$ where liver sequestra have been either removed surgically or discharged spontaneously from a drainage hole a considerable period after the initial injury (Sanders, Macguire, and Moore, 1949; Clarke, 1941; Pilcher, 1942; Thomason, 1952; Cohn, 1947). In none were there any associated abnormal urinary symptoms. (3) Finally, one may therefore ask, 'If damaged liver can produce a nephrotoxin why does it not occur in every case'?

Whereas the mechanism of acute post-traumatic renal failure is not yet fully explained and is probably related to the extent and duration of the traumatic hypotension, it seems most unlikely that a specific nephrotoxin is elaborated by the liver. Incompatible blood transfusion, crushing, shock, and many other complex factors are involved, each of which may play a part in producing this syndrome. In only one of the cases under review did post-operative anuria occur.

\section{CLINICAL FEATURES AND DIAGNOSIS}

When a patient sustains an injury to the liver, he may be killed immediately or die before admission to hospital; he may survive long enough to be admitted to hospital (the common type), or he may present days or even weeks later with delayed manifestations (e.g., abdominal mass, delayed rupture, liver or subphrenic abscess, haemobilia, and so on). It is with the common type that we are concerned and these patients present with varying degrees of shock and abdominal pain.

In this particular series shock was present in varying degree and some patients presented the typical appearance of blood loss. They were pale and sweating with sometimes a tinge of cyanosis of the lips and in others air hunger. One would expect that the degree of shock would bear a direct relationship to the extent of the laceration but this was not so. In one of the cases an elderly man involved in a car accident, who had a blood pressure of $120 / 90 \mathrm{~mm}$. $\mathrm{Hg}$ and a pulse rate of 60 when admitted to hospital, was found at operation to have an extensive inverted $Y$ laceration of the right lobe of the liver. Conversely, a small boy of 11 years who had sustained a 1 in. laceration of the liver, was profoundly shocked on admission. In a more recent review of 21 cases of liver injury, $47.5 \%$ of cases when first seen had systolic blood pressures of over $100 \mathrm{~mm}$. $\mathrm{Hg}$. It is apparent that neither the general appearance of the patient nor the blood pressure readings can be regarded as accurately reflecting the extent of blood loss or of hepatic damage. It would be most unwise to allow either of these uncertain features to affect surgical judgment when it comes to a question of whether or not to explore the abdomen, for the physiological response to blood loss varies considerably from individual to individual.

The abdominal physical signs found in these cases are considerably modified by the presence of associated intra-abdominal injuries. In this series of 30 confirmed cases only $50 \%$ were uncomplicated, and in the remainder the associated organs injured all lay in the upper abdomen close to the liver (stomach 3, jejunum 1, transverse colon 1, omentum and mesentery 4 , spleen 3 , kidney 2 , gall bladder 1 , pancreas 1 , adrenal 1). The majority, therefore, complained of generalized abdominal tenderness most marked perhaps in the upper abdomen or epigastrium. In only six was there pain, tenderness, and rigidity related to the right hypochondrium. On the 
other hand, in an unpublished review of another 21 cases of uncomplicated liver injury, a presumptive pre-operative diagnosis was possible in $85 \%$ of cases, but even so in half of these the main complaint was of generalized abdominal tenderness. On more than one occasion the physical signs were completely misleading for in one case pain was most marked in the left iliac fossa.

\section{OVERALL MORTALITY RATES AND TRENDS}

The mortality rate in subcutaneous liver injury is extremely high. In the present series of 30 confirmed cases, 18 died and 12 survived, giving a mortality rate of $60 \%$. On the other hand, taking the series as a whole, there was a steady decrease in the mortality rate, which coincided with the establishment of a regional blood transfusion service and with the increasing use of whole blood at the earliest possible time (Fig. 3). This overall mortality rate does not compare unfavourably with others found in the literature (Tilton $62.5 \%$; Vance $100 \%$; Lamb $68 \%$; Wright et al. $81.3 \%$; Allen $66 \cdot 6 \%$ ). As would be expected, as the number of associated injuries increased, so did the mortality rate. In the present series Fig. 4 demonstrates this point.

It is commonly held that the mortality rate of closed liver injuries is higher than in penetrating ones. No comparison was possible in the present review for only one case of open injury occurred. This view is based on four critical reviews by Edler (1887), Tilton (1905), Boljarski (1910), and Cohn (1947), each of whom demonstrated that closed liver injuries were associated with about a $40 \%$ higher mortality rate than with open injuries.

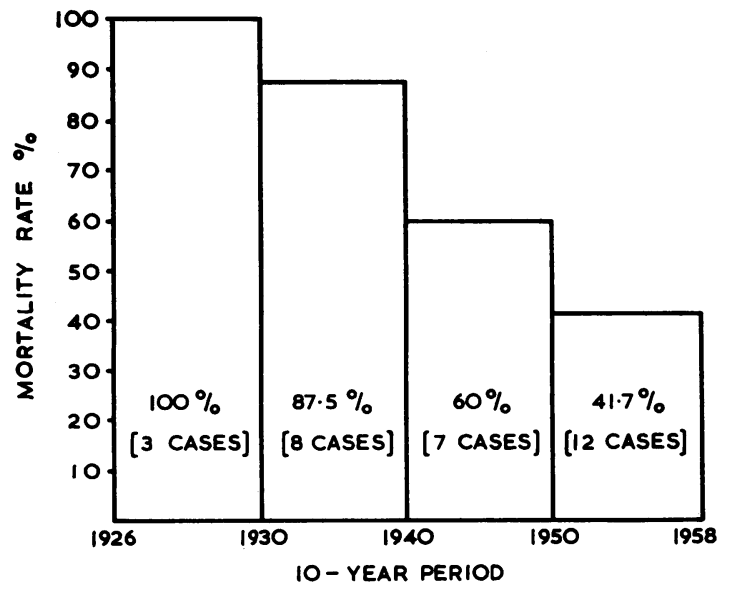

FIG. 3
CAUSES OF DEATH

Of the 18 deaths in this series, there was evidence that in 11 cases no blood transfusions were undertaken or that it was either in inadequate amounts or too late. In fairness it must be stated that these deaths occured mainly in the years between 1926 and 1936 when a regional blood transfusion service was not in existence. Of the remaining seven, three died of complications attributable to uncontrolled biliary leak from the damaged liver. Two developed burst abdominal wounds at 11 and nine days respectively and both died at re-operation for suturing the wound. One collapsed suddenly for no apparent cause, and the other vomited and aspirated the stomach contents into the trachea. The third case developed intestinal obstruction. One patient died on the sixth day of anuria and renal failure; one patient developed a secondary haemorrhage on the ninth day, and one patient survived 56 days, but finally died from associated pulmonary tuberculosis. Finally, one child died shortly after operation and at necropsy the only definite finding was that histologically there was considerable diffuse intrahepatic haemorrhage.

It would seem, therefore, that there are three main causes of death: 1 , Inadequate pre-operative preparation, 2, inadequate control of haemorrhage and biliary leak at operation, and 3, there are some cases in which the intrahepatic damage is so diffuse as to render the prognosis most doubtful. Because of this last fact the surgeon is entirely in the dark and all he can do is the minimum to control further loss of blood and bile. He can offer no prognosis and he must appreciate two things, namely, there is going to be a percentage of patients who die following

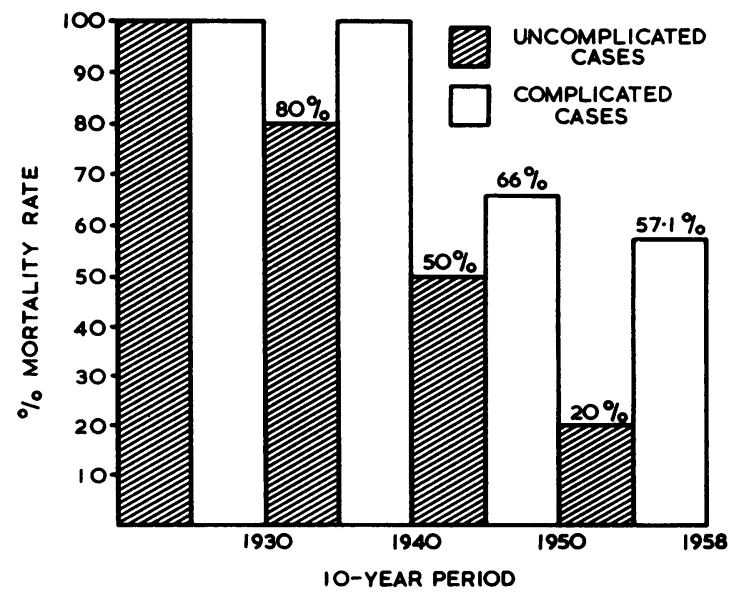

FIG. 4 
successful operation, those with extensive intrahepatic injuries and there is nothing he could have done about it; there is a very small percentage of cases in which complications attributable to intrahepatic necrosis (e.g., abscess, sequestra) may occur. Again nothing can be done about these at operation and he must patiently await the outcome of his initial efforts.

MORTALITY RATE IN RELATION TO TYPE OF TREATMENT

There has been divergence in opinion as to whether or not laparotomy should be undertaken in cases of ruptured liver. The case for a conservative policy hinges on the fact that the portal venous circulation is sluggish and of low pressure and that invariably, at operation, no continuing haemorrhage of any great extent is found. Cases are bound to crop up in which no major breach in intrahepatic venous circulation has occurred, but there are other factors which need most careful consideration before a régime of early surgical intervention is condemned.

The importance of the valveless hepatic veins and their close relationship to the right side of the heart has already been discussed. It is commonly held that bleeding has ceased by the time laparotomy is undertaken. This is not wholly true. It has been my personal experience that while the lacerated area is filled with clot and there is no longer any massive bleeding, there is always a slow but constant trickle into the peritoneal cavity. These clots are friable and most easily detached, but what is most important is that they conceal tributaries of either the portal or hepatic venous systems visible to the naked eye. In three cases I have seen such clots separate following the most gentle manipulations, and this was followed by a pulseless gush of blood from vessels as large as an adult-sized radical artery. With such experience it is difficult to be convinced that conservatism is either justifiable or a sound surgical policy.

Precise diagnosis is frequently impossible. Concomitant injury of liver and spleen manifests itself in exactly the same fashion as if only one was injured, namely, as intra-abdominal haemorrhage. Furthermore, in $50 \%$ of the cases in this series there was an associated injury found at operation.

No recognition has been taken of the fact that if the injury is not treated there is a continuous free flow of bile into the peritoneal cavity, with its own particular risks and consequences. This view is supported by Halberstam, Bloom, and Graham (1947) and Newell (1948), who state that laparotomy is indicated not only in every case of liver injury, but also when such an injury is merely probable, and that 'traumatic rupture of the liver is a dangerous injury. All patients with massive haemorrhage die, usually before surgery can be attempted. All those with acute haemorrhage die, if they are not given the benefit of surgery'. Statistically, three reviews support this opinion.

TABLE III

\begin{tabular}{|c|c|c|c|c|}
\hline \multirow[t]{2}{*}{ Author } & \multicolumn{2}{|c|}{ Cases Operated } & \multicolumn{2}{|c|}{ Cases Not Operated } \\
\hline & No. & Died (\% Mortality) & No. & Died $(\%$ Mortality) \\
\hline \multirow{3}{*}{$\begin{array}{l}\text { Allen (1931) } \\
\text { Wright et al. } \\
\text { (1947) } \\
\text { Mikal and Papen } \\
\text { (1950) }\end{array}$} & 22 & $14(63 \cdot 7)$ & 2 & $2(100)$ \\
\hline & 9 & $5(55 \cdot 5)$ & 17 & $17(100)$ \\
\hline & 7 & $-(38.9)$ & 18 & $-(81 \cdot 8)$ \\
\hline
\end{tabular}

DIFFERENTIAL DIAGNOSIS

This, of course, involves the whole problem of diagnosis of abdominal injuries. In interpreting the physical signs, four factors must be considered: the actual injury to the abdominal wall, the low-grade peritoneal irritation produced by a haemoperitoneum, the more severe type resulting from actual infection of the peritoneal cavity by intestinal contents, bile, or urine, and finally the amount of blood lost.

The localizing physical signs, e.g., the marked tenderness in the right hypochondrium, are probably determined by the site at which the external force strikes the abdominal wall, but which viscus is injured is determined by the direction of this external force. This can be the only explanation for those cases of liver injury in which the physical signs are most marked in a quadrant other than the right hypochondrium, e.g., the left iliac fossa. Haemoperitoneum is productive only of a low-grade peritoneal irritation and the physical signs are dependent entirely upon its extent and its duration. Furthermore, the injury to the abdominal wall may have been diffuse and the differentiation between guarding and rigidity is then difficult.

All that can be said with confidence is that the patient is suffering from an intra-abdominal haemorrhage as the variations in local physical signs are so great. The adoption of a purely academic outlook in the diagnosis and treatment of abdominal injuries, and to say, this is a case of ruptured liver, or this is a case of ruptured spleen and so on, is wrong. In clinical practice we are presented with a patient with an abdominal injury and it is impossible to sort out the clinical features and relate them to one or other organ. There are only two decisions which are required: Whether or not surgery is to be undertaken, and if so, when?

Two things only must be considered: 1 Has the patient lost blood into the peritoneal cavity and is he continuing to lose blood? 2 Are there early signs 
of peritonitis and is it spreading? In so far as those cases are concerned which are admitted with profound shock and blood loss, the decision is obvious, but the difficulty arises where the degree of haemorrhage or peritoneal irritation is minimal. The signs of haemoperitoneum are slight, productive only of mild generalized tenderness with slight guarding or diminution in bowel sounds, and the compensatory ability of some patients is so great that up to 3 pints of blood can be lost without much alteration in blood pressure and pulse rate. Even if these minimal signs are present and a liver injury is suspected, for the foregoing reasons, because the patient is being operated on when his general condition is relatively good, early surgery is to be recommended.

If for some reason or another a decision is made to observe the patient, then a rising pulse rate is an earlier and more accurate assessment of blood loss than change in blood pressure. Similarly as a reflection of the development of peritonitis of any degree, alteration in the quality, or absence of bowel sounds, is the most important physical sign.

The presence of haematuria or multiple fractured ribs must not be allowed to deter a surgeon from operating. This is a great diagnostic pitfall and if the abdominal physical signs leave the slightest possible doubt that some intra-abdominal injury has taken place, then laparotomy should be performed. Considerable judgment is required to decide whether operation is needed or not, but any deterioration in the general or local condition of the patient warrants the most serious consideration of laparotomy. There is no disgrace in operating and finding nothing.

\section{TREATMENT}

From what has been said in the previous sections and if the policy of early surgical intervention is accepted, then treatment must be directed towards early and adequate replacement of the blood lost, early control of bleeding, and at the same time control of biliary outflow or the provision of adequate external drainage from the lacerated area. No further comment will be made on the question of transfusion, only to repeat that in 11 of the 18 deaths in this series death was attributable either to delay or inadequacy of blood replacement. When operation is undertaken the whole abdominal cavity must be systematically examined to exclude any other injury.

There remain to be discussed details of surgical technique and it is around this point that there has probably been the greatest controversy of all. There is one important feature which must be emphasized above all else. If hepatic surgery is to be undertaken, a needle long enough to be passed through the whole thickness of the liver must be available. A Kous- netzoff needle is not an instrument available in all theatres, whereas a 9 in. silver malleable probe with an eye will prove more valuable than the largest available needle of the ordinary variety.

SURGICAL APPROACH Grey Turner's (1940) advice must always be borne in mind: 'The patient will not die from a very big incision, but may very likely succumb if some important injury is overlooked .... In this respect the question arises whether or not there is justification under certain circumstances in converting a simple upper abdominal incision into a thoraco-abdominal one.

The crux of the matter seems to be, Is it going to be of any value? If on palpation a deep cleft which is bleeding severely can be demonstrated, and it is felt that this would be amenable to some form of suturing, then there can be no reason for not doing this, for suturing is preferable to packing. On the other hand, if a stellate or grossly comminuted injury is felt, in which suturing would be out of the question, then there is no point in doing it and packing should be resorted to. The additional risks of a thoracoabdominal incision must be weighed against the risks of closing the abdomen with bleeding incompletely controlled.

TREATMENT OF THE LIVER WOUND There can be no uniform method applicable to all varieties of liver injury. These wounds vary in size and depth, and may be simple surface breaches of Glisson's capsule, full-thickness divisions, or stellate and comminuted injuries with variable degrees of separation. The specific measures which must be considered are debridement, packing, suturing, drainage, or a combination of all.

Debridement That there is a place for the removal of almost completely or completely detached segments of liver, whose viability is in doubt, cannot be denied, for they are potentially sources of infection. The fulfilment of this ideal may be difficult, for there is not only the worry of having to accomplish haemostasis from a newly created raw surface, but there is the worry of extending the surgical procedure in a patient who is already critically ill. In this series what liver was removed was either free, small, or fragmented. In the case in which deep fissures are present which extend through most of the liver substance, the additional risks of removal may well be preferable to re-attaching them, so running the risks of repeated secondary haemorrhages which are even more difficult to control and may necessitate the use of a thoraco-abdominal approach. This view is supported by the experience of Sanders et al., who, in two cases in which a deep laceration of the lateral third of the right hepatic lobe was present, had to operate a second time, using a thoraco-abdominal 
approach to control secondary haemorrhage from the necrosed fragments of liver which had been re-attached to the main bulk of the liver at the first operation. There seems to be one exception to this, namely, deep lacerations immediately to the left of the falciform ligament where the whole of the left lobe of the liver has been detached. This is the site at which the portal veins and hepatic vessels bifurcate and where there is a probability that the detached fragment has retained its blood supply. The porta hepatis should be carefully examined to determine this point before suturing is undertaken. Such a procedure was performed with success in two cases in this series.

Packing Packing is one of the traditional methods of controlling haemorrhage in liver injuries. Three substances have been used, namely, gauze, local tissues (falciform ligament, omentum, muscle), and synthetic coagulants.

Gauze packing was associated with the highest mortality rate in this series. Of the eight patients in whom it was used, five died. If packing is to be resorted to, it must be placed in a position in which it can exert pressure and not be easily dislodged. The only part of the liver in which this can occur is the dome, where the space between liver and diaphragm is so small that it can exert effective pressure and remain where it has been placed. On the undersurface packing moves every time the patient breathes and it soon becomes dislodged and ineffective. If it is used in such a situation it then becomes nothing more than a gesture. The use of packing is therefore indicated in cases of comminution of the liver not amenable to suturing, in the dome, or posterior surface, and it is obviously of value in those patients whose general condition is so critical that the operation must be abandoned with haste. Quite apart from this, other theoretical objections have been raised against packing. 1 It must be tight or it is of no use: if too tight it will produce pressure necrosis and favour secondary haemorrhage. 2 It tends to dam any flow of bile and is a potential source of infection leading to localized pockets of bile, abscesses, hepatitis, subphrenic infection, and increases the risk of chest complications (Madding, 1955).

Local tissues have been used in an effort to avoid a gauze pack. However, they are often difficult to reflect into position and if they are to be effective need to be used as free grafts. Synthetic coagulants are useful in the control of superficial laceration either alone or in combination with suturing. Their use, however, in large amounts or in deep lacerations in combination with suturing must be regarded with some caution for their rate of absorption is slow and may exceed the period required for healing; they are not always absorbed and may lead to their own quota of post-operative complications. These have included subphrenic abscess, hepatic abscesses, intestinal obstruction from adhesions, and the erosion of the oxidized cellulose through the intestinal wall.

Suturing This is undoubtedly the most effective means of both controlling haemorrhage and biliary drainage, and should be employed whenever possible. Two types of injury seem to lend themselves to this form of treatment: the linear full-thickness and partial-thickness injuries. Preliminary occlusion of the vessels lying in the free edge of the lesser omentum will help to reduce the amount of bleeding from the raw liver surface, but not completely, for that does not control any back flow from the hepatic veins. Before suturing, attempts should be made to identify and ligate any major vascular radicals visible on the surface, and when such suturing is finally undertaken it should be not merely across a wound, for such stitches have no effect whatsoever in controlling either biliary outflow or further haemorrhages. The important sutures are those which run parallel with the wound edges, for it is these which compress the vascular and biliary channels. If sutures are placed parallel with the torn surfaces and effect haemostasis, then the liver substance lying between those sutures and the tear is liable to undergo necrosis. It is difficult to see any alternative and the risk of possible necrosis must be accepted as the price to be paid for effective haemostasis. (On several occasions I have placed such sutures $\frac{1}{2}$ in. from the tear and have found that not only do the sutures hold well, but that no complication which has been mentioned has occurred.) When considerable fissuring is present, attempts at suturing are not always successful, but even so, considerable patching of these wounds can sometimes be accomplished. When resection of devitalized tissue has been undertaken, suturing is of course essential in an attempt to control bleeding from the torn surface.

One last consideration is that it has been shown that the tight closure of these lacerations may lead to certain complications. A closed cavity may be created within which blood, bile, or pus may accumulate, leading to cyst or abscess formation or the syndrome of traumatic haemobilia. On this account Kreig (1936), Hawthorne, Oaks, and Neese (1941), and Sparkman (1953) suggested that a small drain should be inserted into the depths of a sutured hepatic laceration.

Drainage Although drainage was not undertaken in many cases in this series, without adverse complications, it cannot be regarded as a good surgical practice. Omission to drain can only be attributed to failure to appreciate the fundamental pathology or to the supreme confidence of the 
operator that further biliary leak has been prevented. The biliary radicals are small, difficult to detect even at necropsy, and neither the appearances nor the size of the wound can give any indication of the possible amount of further biliary flow. In addition, there is always the question of possible necrosis. The placing of drains, not only in appropriate positions on the surface of the liver, but also when the occasion demands, in the liver substance itself, must be regarded as being one of the most important features in the management of liver injuries.

\section{SUMMARY AND CONCLUSIONS}

Clinical research which involves not only the collection and analysis of a given number of cases, but also the comparison of results obtained with those in other published series, is always beset with difficulties. Apart from the question of gathering in these cases, it is invariably found that there are gaps in the recording of the details regarded as being essential in the preparation of any statistical analysis. So it has been with this series. It has been impossible to produce figures of such accuracy that they would withstand a truly scientific criticism. Quite apart from this, there are 'clinical' features such as the individual patient's reaction to blood loss, and surgical and anaesthetic skill, which are so varied that it is impossible to translate them into terms which can be expressed or recorded as graphs or figures. One is left only with impressions and individual opinions.

In the introductory paragraph of this paper certain questions were posed, and, bearing in mind what has been said, the conclusions arrived at are as follows:

Liver injuries are uncommon. They occur in between 1 in 1,300 and 1 in 4,000 cases admitted to hospital. Hepatic injury occurs if not with equal, then with slightly greater frequency than splenic injury, but which is injured when a patient is involved in an accident is a matter of chance, for both these organs lie closely together in the upper abdomen and whether one or the other or both are damaged depends on the site, direction, and extent of injury. Attention is drawn to the difficulties of precise diagnosis and that in these cases multiple intraabdominal injuries may often be sustained.

The greatest single cause of death is haemorrhage and shock, but late complications following operation can be attributed mainly to a continued biliary leak from the torn liver surface.

The mortality rate is still high in closed liver injuries. In this series the overall mortality rate is $60 \%$ and this compares favourably with figures obtained in other series.

The one pathological feature not always appreciated is that the surface laceration is only part of varying degrees of generalized liver damage, and that although the regenerative powers of the liver are excellent, on occasions the intrahepatic damage may be so extensive that death occurs shortly after an apparently successful operation.

There is no one correct treatment, especially where the actual technique of hepatic haemostasis is concerned. Packing if possible should be avoided, but if it has to be resorted to, it must be placed in a position where not only will it remain but where it will exert pressure. The only place where this can occur is over the dome and posterior surface. Suturing is to be preferred and should be used whenever possible.

There is a place for more radical surgery on a few occasions. Where a segment of liver is almost completely detached it should be removed, and where a freely bleeding laceration at the dome or posterior surface is detected and it is felt to be amenable to suturing, then there is justification for converting a simple laparotomy into a thoraco-abdominal exploration to ensure good vision for effective haemostasis.

The most important single factor which can reduce the overall mortality rate is the early and adequate transfusion of whole blood. Early operation is considered advisable, and although on a few occasions resection of hepatic tissue may be necessary, in general the simpler the technique used to control both haemorrhage and biliary effusion, the better. Drainage of the peritoneal cavity is considered to be not only good surgical practice, but essential in cases of liver injury.

This work was undertaken at the suggestion of Professor Lambert Rogers, Director of Surgical Studies, University of Wales. I am most grateful to him for his kindly criticism and help.

I wish to thank the following surgeons for permission to quote their case histories: Messrs. Melbourne Thomas, R. J. Williams, Wynford Davies, and S. Bloom. The remaining cases were collected for me by Mr. Morgan, the Medical Records Officer of the Cardiff Royal Infirmary.

I am grateful to Miss Joan Beard for her patience and the care with which she has undertaken the typing and checking of this work.

\section{REFERENCES}

Allen, A. W. (1931). Internal injuries without penetrating wounds. New Engl. J. Med., 205, 34-38.

Boljarski, N. (1910). Ueber Leberverletzungen in Klinischer und experimenteller Hinsicht, unter besonderer Berücksichtigung der isolirten Netzplastik. Arch. klin. Chir., 93, 507-547. (Cited by Thorlakson and Hay.)

Boyce, F. F. (1941). The Role of the Liver in Surgery. Charles C. Thomas, Springfield, Illinois.

Clarke, R. (1941). A case of liver 'sequestrum' complicating subcutaneous rupture of the liver. Brit. J. Surg., 28, 544-548.

(1954). Closed abdominal injuries. Lancet, 2, 877-885. 
Cohn, R. (1947). The treatment of traumatic injuries of the liver. Stanf. med. Bull., 5, 120-124.

Edler, L. (1887). Die traumatischen Verletzungen der parenchymatösen Unterleibsorgane. Arch. klin. Chir., 34, 343-409. (Cited by Tilton, B. J.)

Gans, H. (1955). The Anatomy of the Intrahepatic Structures and its Repercussions on Surgery. Elsevier Publishing Co., Amsterdam and New York.

Grey Turner, G. (1940). Some notes on abdominal injuries. Brit. med. J., 1, 679-682.

Halberstam, C., Bloom, J., and Graham, A. (1947). Laceration of the liver. Industr. Med., 16, 52-57.

Hawthorne, H. R., Oaks, W. W., and Neese, P. H. (1941). Liver injuries with a case report of repeated hemorrhages through the biliary ducts. Surgery, 9, 358-460.

Helwig, F. C., and Orr, T. G. (1932). Traumatic necrosis of the liver with extensive retention of creatinine and high grade nephrosis. Arch. Surg. (Chicago), 24, 136-144.

Hinton, J. W. (1929). Injuries to the abdominal viscera. Ann. Surg., 90, 351-356.

Kreig, E. G. (1936). Hepatic trauma. Analysis of 60 cases. Arch. Surg. (Chicago), 32, 907-914.

Lamb, C. A. (1939). Rupture of the liver. New Engl. Med.J., 221,855-859.

Lewis, D., and Trimble, I. R. (1933). Subcutaneous injuries of the abdomen. Ann. Surg., 98, 685-697.

Madding, G. F. (1955). Injuries of the liver. A.M.A. Arch. Surg., 70, 748-756.

Mikal, S., and Papen, G. W. (1950). Morbidity and mortality in ruptured liver. Surgery, 27, 520-525.
Musselman, M. M., Glas, W. W., and Campbell, D. A. (1955). Hepatic injuries. Amer. J. Surg., 89, 748-752.

Newell, C. E. (1948). Traumatic rupture of the gall bladder and liver. Report of a case with generalised bile peritonitis. Ibid., 76, 466-471.

O'Neill, J. N. (1941). Traumatic rupture of the liver. Calif. west Med., $54,68-70$.

Orr, T. G., and Helwig, F. C. (1939). Liver trauma and hepatorenal syndrome. Ann. Surg., 110, 682-692.

Papen, G. W., and Mikal, S. (1950). Liver trauma. Rev. Gastroent., 17, 633-642.

Pilcher, L. S. (1942). Massive rupture of the liver. Ann. Surg., 116 , 827-832.

Sanders, G. B., Macguire, C. H., and Moore, R. H. (1949). Massive rupture of the liver. Amer. J. Surg., 78, 699-705.

Sparkman, R. S. (1953). Massive hemobilia following traumatic rupture of the liver. Ann. Surg., 138, 899.

Thomason, T. H. (1952). Massive rupture of the liver. Texas J. Med., 48, 824-826.

Thorlakson, P. H. T., and Hay, A. W. S. (1929). Rupture of the liver. Canad. med. Ass. J., 20, 593-598.

Tilton, B. T. (1905). Some considerations regarding wounds of the liver. Ann. Surg., 61, 20-30.

Vance, B. M. (1928). Subcutaneous injuries of the abdominal viscera. Anatomic and clinic characteristics. Arch. Surg. (Chicago), 16, 631-679.

Wright, L. T., Prigot, A., and Hill, L. M. (1947). Traumatic rupture of the liver without penetrating wounds. A study of 32 cases. Ibid., 54, 613-632.

\section{The June 1961 Issue}

\section{THE JUNE 1961 ISSUE CONTAINS THE FOLLOWING PAPERS}

The diagnosis and treatment of peptic oesophagitis GEOFFREY WOOLER

The turnover and shedding of epithelial cells $B$. CREAMER, R. G. SHORTER, and JOHN BAMFORTH

Part I The turnover in the gastro-intestinal tract

Part II The shedding in the small intestine

The influence of cortisone on the parietal cell population of the stomach in the dog N. C. R. W. REID, R. M. HACKETT, and R. B. WELBOURN

The measurement of gastrointestinal protein loss by a new method $K$. N. JEEJEEBHOY and N. F. COGHILL

The stability of the radiotriolein bond in intestinal secretions A. G. COX and Z. HINCHLIFFE

Proctalgia fugax HASSAN IBRAHIM

Iron deficiency after partial gastrectomy J. R. HOBBS

Some metabolic and haematological effects of oesophago-jejunostomy with by-pass of the stomach SHEILA T. CALLENDER, L. J. WITTS, P. R. ALLISON, and A. GUNNING
A clinical appraisal of the treatment of chronic duodenal ulcer by vagotomy and gastric drainage operation $w$. GERALD AUSTEN and HAROLD $c$. EDWARDS

Gastric acid secretion and mucosal appearances in Addison's disease and hypopituitarism A. W. M. SMITH, I. W. DELAMORE, and A. WYNN WILLIAMS

Studies on the site of fat absorption 2 Fat balances after resection of varying amounts of the small intestine in man C. C. BOOTH, D. ALLDIS, and A. E. READ

\section{Methods and techniques}

The motility of the pelvic colon 1 Motility in normals and in patients with asymptomatic duodenal ulcer A. M. CONNELL

Potassium replacement therapy G. N. CHANDLER, C. HETHERINGTON, A. N. STEPHENSON, and M. ATKINSON

A method of measuring gastric pressure during vagotomy PETER A. CLARKE

Copies are still available and may be obtained from the PUBLISHING MANAGER, BRITISH MEDICAL ASSOCIATION, TAVISTOCK SQUARE, W.C.1, price 17s. 6D. 